\title{
Effect of Aging on Fatty Streak Formation in a Diet-Induced Mouse Model of Atherosclerosis
}

\author{
Yuhua Li ${ }^{a, b}$ Timothy R. Gilbert ${ }^{a, b}$ Alan H. Matsumoto ${ }^{a}$ Weibin Shi $^{a, b}$ \\ Departments of a Radiology and ${ }^{b}$ Cardiovascular Research Center, University of Virginia, Charlottesville, Va., USA
}

\section{Key Words}

Atherosclerosis $\cdot$ Adhesion molecule $\cdot$ Fatty streak formation

\section{Abstract}

Age is considered to be a major risk factor for atherosclerosis, but it is unclear whether age has a direct effect on susceptibility to atherosclerosis. Wild-type mice develop fatty streak lesions in the aortic root only when fed a cholate-containing high fat/cholesterol diet. To investigate the influence of age on fatty streak formation, young (10 weeks) and old (53 weeks) female C57BL/6 mice were fed an atherogenic diet containing $15 \%$ fat, $1.25 \%$ cholesterol and $0.5 \%$ sodium cholate for 12 weeks. Atherosclerotic lesions at the aortic root were measured after cryosections were stained with oil red O. Results showed that old mice developed a comparable size of aortic lesions with young counterparts $(5,600 \pm 2,480$ vs. $6,457 \pm 1,537 \mu \mathrm{m}^{2} /$ section; $p=0.77$ ), although old mice had significantly higher plasma cholesterol levels than young mice on the atherogenic diet $(p<0.05)$. Plasma levels of soluble vascular cell adhesion molecule 1 were significantly higher in old mice than in young mice on both chow and Western diets $(p<0.005)$. These data indicate that age has no direct effect on atherosclerosis susceptibility although it is accompanied by elevations in plasma cholesterol and vascular cell adhesion molecule 1 levels in C57BL/6

\section{KARGER}

(c) 2007 S. Karger AG, Basel

Fax +41613061234

E-Mail karger@karger.ch

www.karger.com mice. Thus, increased cardiovascular events with age are probably related to a progressive increase in plaque size rather than to an increase in atherosclerosis susceptibility.

Copyright $\odot 2007$ S. Karger AG, Basel

\section{Introduction}

Atherosclerotic cardiovascular disease is an age-dependent disease. Although this disease starts early in life, its symptoms and complications usually manifest in midlife. The increased clinical incidence with age may be attributed to an increased susceptibility to atherosclerosis or to a progressive increase in plaque size, but it may also be simply due to increased exposure to risk factors leading to plaque rupture and the subsequent thrombosis that causes clinical events.

Previous studies dealing with the effects of aging on atherosclerosis have produced conflicting results among different species and even in the same species treated under different experimental conditions. For example, aged rabbits receiving a low-dose hypercholesterolemic diet $(0.25 \%$ cholesterol) for 18 months had aortic atherosclerotic lesions which were of a larger size and more complicated than those observed in young rabbits, despite comparable serum cholesterol levels $[1,2]$. In contrast, Cortes
Dr. Weibin Shi

Department of Radiology, University of Virginia, MR4 Room 117

Box 801339, 409 Lane Road

Charlottesville, VA 22908 (USA)

Tel. +1 434243 9420, Fax +1 434982 5680, E-Mail ws4v@virginia.edu 
et al. [3] reported that when challenged with a cholesterol-rich diet (1\% cholesterol) for 2 months, aortic atherosclerotic lesions are more prominent in young than in old rabbits. The mouse is increasingly used for experimental atherosclerosis research. However, wild-type mice are highly resistant to atherosclerosis. Even the most susceptible C57BL/6 mice only develop fatty streak lesions at the aortic root when they are fed an atherogenic diet containing high fat/cholesterol and sodium cholate [4]. This feature of atherosclerotic lesion formation makes wild-type mice an ideal model for studying the age-related effect on atherosclerosis. In contrast, apolipoprotein-E-deficient and low-density lipoprotein (LDL) receptor-deficient mice develop spontaneous hyperlipidemia and atherosclerosis in a time-dependent manner even on a regular chow diet, thus making it difficult to evaluate the effect of aging on atherosclerotic lesion formation.

Aging is associated with increased inflammatory activity in the arterial wall, including increased expression of adhesion molecules such as vascular adhesion molecule 1 (VCAM-1) [5]. Because adhesion molecules function to recruit monocytes from circulation, in the present study, we also tested the hypothesis that increased expression of this adhesion molecule in the arterial wall would promote atherosclerotic lesion formation in aged animals.

\section{Materials and Methods}

\section{Mice}

Young and old female C57BL/6 mice were purchased from the Jackson Laboratory, Bar Harbor, Me., USA. The animals were weaned at 4 weeks of age and maintained on a rodent chow diet. At 10 weeks (young group) or 53 weeks (old group) of age, mice were switched onto an atherogenic diet containing $15 \%$ fat, $1.25 \%$ cholesterol and $0.5 \%$ cholic acid (the Paigen diet, TD 90221, FoodTek, Inc.) and maintained on the diet for 12 weeks, as previously reported [6,7]. Mice were bled twice: once before initiation of the Paigen diet and once at the end of the diet. All procedures were carried out in accordance with current National Institutes of Health guidelines and approved by the Institutional Animal Care and Use Committee.

\section{Plasma Lipid Measurements}

Mice were fasted overnight before blood was collected through retro-orbital veins under isoflurane anesthesia. Plasma total cholesterol, high-density lipoprotein (HDL) cholesterol and triglyceride levels were measured by enzymatic assays as previously described by Tian et al. [8].

Aortic Lesion Analysis

Methods for the quantification of atherosclerotic lesions in the aortic root were as previously reported [9]. Briefly, the heart and proximal aorta were excised and embedded in optimal cutting temperature compound. Serial $10-\mu \mathrm{m}$-thick cryosections from the middle portion of the ventricle to the aortic arch were collected and mounted on poly-D-lysine-coated slides. In the region extending from the appearance to the disappearance of the aortic valves, every other section was collected. In all other regions, every fifth section was collected. Sections were stained with oil red $\mathrm{O}$ and hematoxylin and counterstained with fast green, and the lesion areas were counted by light microscopy.

\section{Measurements of Soluble VCAM-1}

ELISA kit for soluble mouse VCAM-1 assay was purchased from R\&D Systems, and the assays were performed by following the manufacturer's instructions.

\section{Western Blot Analysis for VCAM-1}

Expression of VCAM-1 in the aortic wall when mice were fed the chow diet was determined by Western blot analysis. Aorta protein was prepared as previously described [10]. Briefly, the aorta was washed thoroughly with phosphate-buffered saline containing $5 \mathrm{U} / \mathrm{ml}$ heparin and $1 \mathrm{~mm}$ EDTA through the heart, cleaned of periadventitial fat and connective tissues, and snapfrozen in liquid nitrogen. The frozen aorta was mechanically broken up, dispersed in lysis buffer containing $10 \mathrm{~mm}$ Tris, $\mathrm{pH} 8$, $1 \mathrm{~mm}$ EDTA, $2.5 \%$ sodium dodecyl sulfate and 5\% mercaptoethanol, and centrifuged at $500 \mathrm{~g}$ for $10 \mathrm{~min}$ at $4^{\circ} \mathrm{C}$. The supernatant was collected and used for detection of VCAM-1. Aorta protein $(10 \mu \mathrm{g})$ was separated by electrophoresis on $4-12 \%$ Tris polyacrylamide gels and electrophoretically transferred onto polyvinyl difluoride membranes (Invitrogen). The membranes were incubated with primary antibodies to mouse VCAM-1 (R\&D Systems) or glyceraldehyde-3-phosphate dehydrogenase (GAPDH; Chemicon International) overnight and then incubated for $0.5 \mathrm{~h}$ with alkaline-phosphatase-conjugated secondary antibodies. Signals were detected by the chemiluminescence method (Invitrogen).

Statistical Analysis

All values were expressed as means \pm SEM. Student's t test was used to determine the statistical differences between old and young mice in all measurements. Differences were considered statistically significant at $\mathrm{p}<0.05$.

\section{Results}

\section{Effect of Age on Atherosclerotic Lesions}

To determine the effect of age on fatty streak formation, 10-week-old (young) and 53-week-old (old) female C57BL/6 mice were fed the atherogenic diet for 12 weeks. Lesion formation in the aortic root was examined after cross-sections were stained with oil red $\mathrm{O}$. As shown in figure 1 , the lesions in both old and young mice were small and intensely stained with oil red $\mathrm{O}$, suggesting they were fatty streak lesions. The lesion area in old mice was 5,600 $\pm 2,480 \mu \mathrm{m}^{2} / \mathrm{section}(\mathrm{n}=15)$, which was comparable with the area of $6,457 \pm 1,537 \mu \mathrm{m}^{2} /$ section in young mice $(n=14 ; p=0.77)$ (fig. $2 a)$. The study was re- 
Fig. 1. Representative light photomicrographs of atherosclerotic lesions in the aortic root of old and young female C56BL/6 (B6) mice. Mice were fed an atherogenic diet containing high fat/cholesterol and cholate for 12 weeks. The aortic root was cross-sectioned, stained with oil red $\mathrm{O}$ and hematoxylin, and counterstained with fast green. Original magnification $\times 10$.

Fig. 2. Quantitative comparisons of atherosclerotic lesion sizes at the aortic root of old and young female B6 mice. Mice were fed the atherogenic diet for 12 weeks. Values are means \pm SEM. In the first study (a), 15 old mice and 14 young mice were used for lesion analysis. In the second study (b), 15 mice from each group were analyzed.

Fig. 3. Plasma levels of total cholesterol (chol.), HDL cholesterol and triglyceride of old and young mice when fed chow or atherogenic diet. Blood was obtained after overnight fasting. Values are means \pm SEM for $4-15$ mice. * $\mathrm{p}<0.05$ versus young mice.
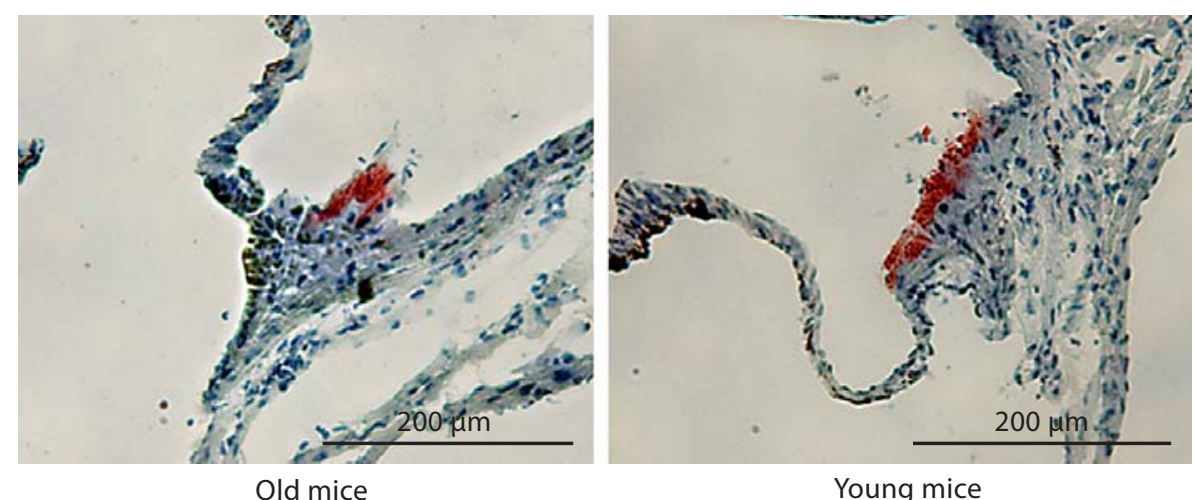

Young mice
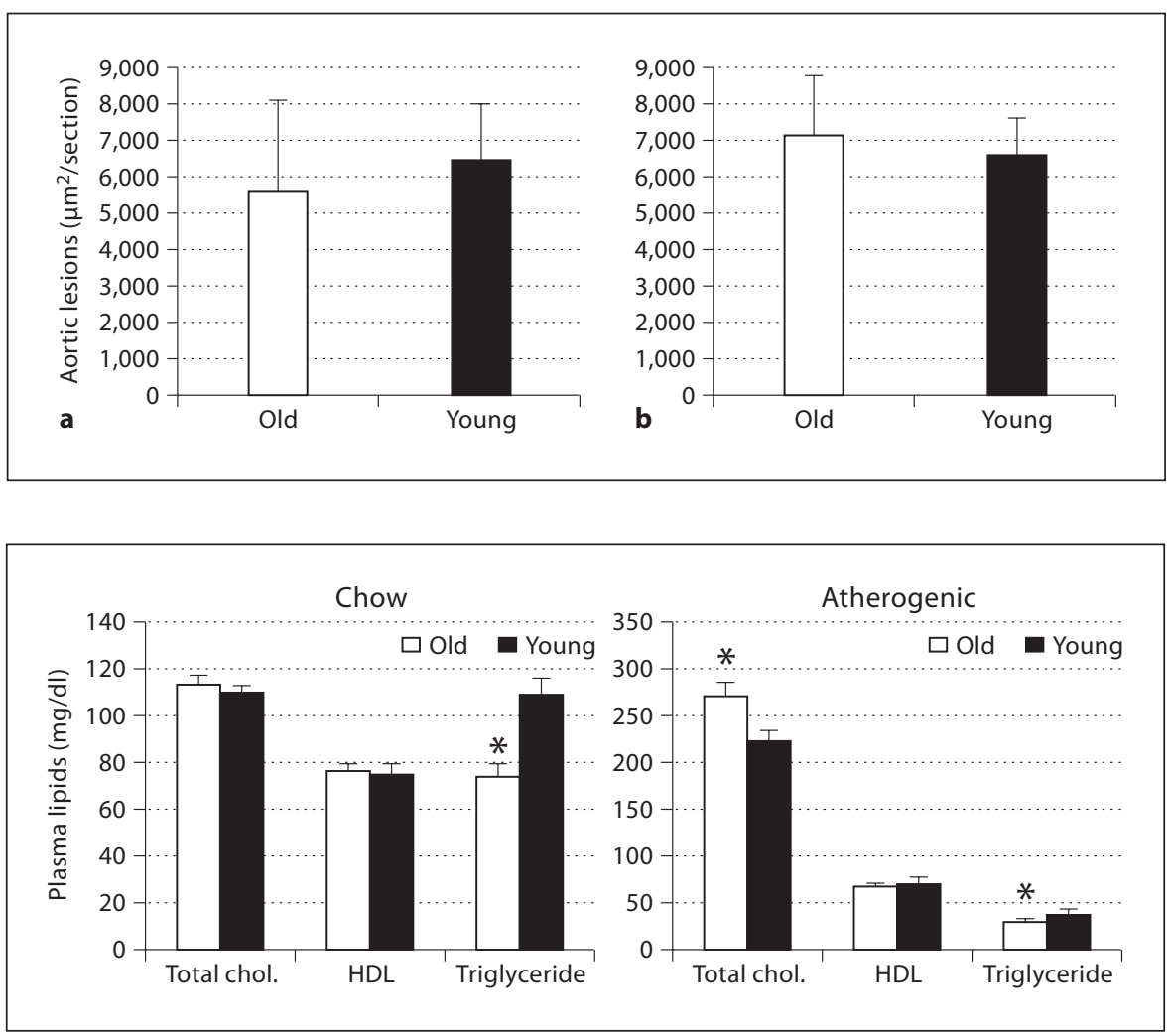

peated, whereby 15 old and 15 young mice were fed the atherogenic diet for 12 weeks and examined for aortic lesion formation. The lesion areas of the old and young mice were 7,157 $\pm 1,594$ and $6,575 \pm 1,035 \mu \mathrm{m}^{2}$, respectively ( $p=0.76$; fig. $2 b$ ). These lesion areas were similar to the areas quantitated in the first set of animals.

\section{Effect of Age on Plasma Lipid Levels}

Plasma levels of total cholesterol, HDL cholesterol and triglyceride were measured before and 12 weeks after mice were fed the atherogenic diet. On the chow diet, old $(\mathrm{n}=12)$ and young mice $(\mathrm{n}=10)$ had comparable levels of total $(113.3 \pm 3.6 \mathrm{vs} .109 .1 \pm 3.5 \mathrm{mg} / \mathrm{dl} ; \mathrm{p}=0.41)$ and HDL cholesterol $(76.0 \pm 2.7$ vs. $74.7 \pm 4.3 \mathrm{mg} / \mathrm{dl} ; \mathrm{p}=$ 0.80) (fig. 3). On the atherogenic diet, total cholesterol levels were significantly higher in old mice than in young mice $(275.2 \pm 13.6$ vs. $223.8 \pm 10.5 \mathrm{mg} / \mathrm{dl} ; \mathrm{p}=0.0064$; $\mathrm{n}=14$ for each group). Since HDL levels were comparable between the 2 age groups $(67.4 \pm 4.0$ vs. $71.1 \pm 5.7 \mathrm{mg} / \mathrm{dl}$; $\mathrm{p}=0.61$ ), the difference in total cholesterol levels should be attributed to changes in the non-HDL fraction. Old mice had significantly lower plasma triglyceride levels than young mice on both chow $(73.2 \pm 6.4$ vs. $108.8 \pm$ $7.0 \mathrm{mg} / \mathrm{dl} ; \mathrm{p}=0.007 ; \mathrm{n}=4$ or 5$)$ and atherogenic diets $(29.7$ 


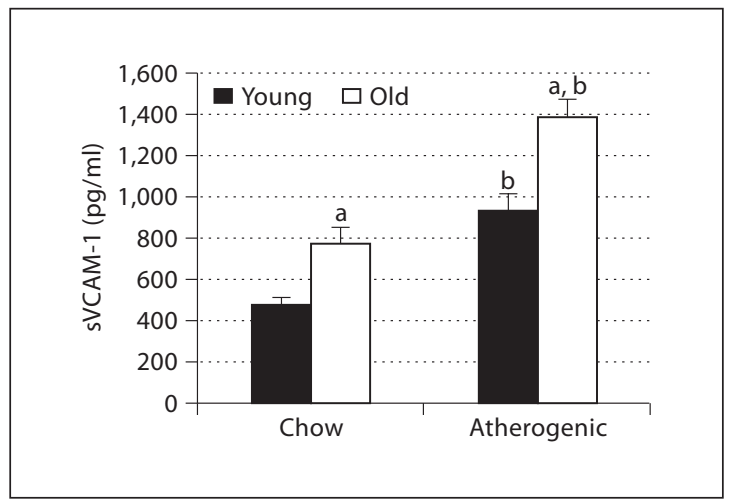

Fig. 4. Plasma levels of soluble VCAM-1 (sVCAM-1) in old and young B6 mice when fed chow or atherogenic diet. Values are means \pm SEM for $4-8$ mice. ${ }^{a} \mathrm{p}<0.05$ versus young mice; ${ }^{b} \mathrm{p}<0.05$ versus chow diet.

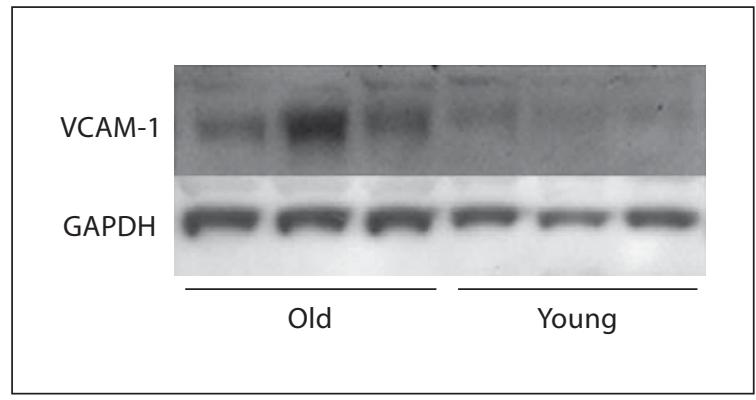

Fig. 5. Western blot analysis of VCAM-1 and GAPDH expression in the descending aorta when mice were fed a chow diet. Each lane represents an individual mouse. Aorta protein $(10 \mu \mathrm{g})$ was electrophoresed on Tris polyacrylamide gels, transferred to nitrocellulose membranes and probed with antibodies for the proteins.

\pm 2.7 vs. $38.1 \pm 2.6 \mathrm{mg} / \mathrm{dl} ; \mathrm{p}=0.033 ; \mathrm{n}=14$ for both groups). Compared with the chow diet, the atherogenic diet resulted in a significant reduction in triglyceride levels in both young and old mice $(\mathrm{p}<0.05)$.

\section{Soluble VCAM-1 Levels in Plasma}

Plasma VCAM-1 levels of young and old mice before and 12 weeks after the atherogenic diet were measured by ELISA (fig. 4). Old mice had significantly higher soluble VCAM-1 levels than young mice on both chow $(776 \pm 78$ vs. $479 \pm 33 \mathrm{ng} / \mathrm{ml} ; \mathrm{p}=0.017 ; \mathrm{n}=4$ or 5 for each group) and atherogenic diet $(1,389 \pm 87$ vs. $937 \pm 77 \mathrm{ng} / \mathrm{ml}$; $\mathrm{p}=0.0016 ; \mathrm{n}=8$ for each group). Also, feeding of the atherogenic diet significantly elevated plasma VCAM-1 levels for both young and old mice $(\mathrm{p}<0.05)$.

\section{VCAM-1 Expression in the Descending Aorta}

The presence of VCAM-1 in the descending aorta when mice were fed the chow diet was examined by Western blot analysis (fig. 5). The expression level of VCAM-1 was slightly higher in old compared with young mice (VCAM-1/GAPDH ratio: $0.17 \pm 0.05$ vs. $0.14 \pm 0.07$; $\mathrm{n}=3$ ), although the difference was not statistically significant $(\mathrm{p}=0.17)$.

\section{Discussion}

In the present study, we determined the effect of age on atherosclerotic lesion formation, plasma lipid levels and VCAM-1 expression using a dietary mouse model of atherosclerosis. Both young (10 weeks old) and old (53 weeks old) C57BL/6 mice were fed an atherogenic diet for 12 weeks. The major finding of this study was that age had no influence on atherosclerosis susceptibility although plasma total cholesterol and soluble VCAM-1 levels increased significantly with age in the mice.

The symptoms and complications of atherosclerosis usually manifest in midlife. The young and old mice used in this study were 10 and 53 weeks of age. After being fed the atherogenic diet for 12 weeks, the 2 groups of mice were 22 and 65 weeks old, respectively, comparable with teens and mid fifties in human life [11]. Similar experiment designs have been reported in previous studies [13]. We took advantage of the dietary model in which atherosclerosis occurs only when mice are fed an atherogenic diet containing high fat/cholesterol and cholate. On a rodent chow diet, wild-type mice have a lipoprotein profile that consists almost entirely of HDL. This explains the total resistance of wild-type mice on the chow diet to atherosclerosis. On the atherogenic diet, both old and young mice developed moderate hypercholesterolemia and formed fatty streak lesions at the aortic root. The current finding that old and young mice developed similar sizes of aortic lesions suggests that age has no effect on atherosclerosis susceptibility. In contrast, a previous study reported that old LDL receptor-deficient mice developed more atherosclerosis than young counterparts [9]. Since LDL receptor-deficient mice display mild hypercholesterolemia with a plasma cholesterol level of approximately $300 \mathrm{mg} / \mathrm{dl}$ and develop spontaneous atherosclerosis on a chow diet, it is not surprising that old mice would have more atherosclerosis than young mice. In consistence with our current observation is a more recent study reporting that young rabbits receiving a short-term high-cholesterol diet ( $1 \%$ cholesterol) developed larger 
aortic lesions than old counterparts [3]. Female mice were used for the study because they develop much larger atherosclerotic lesions than their male counterparts [12]. The present results may not be extrapolated to male mice because they were not studied.

In the present study, mice were fed with the atherogenic diet for 12 weeks. Our previous studies have shown that at this stage, C57BL/6 mice develop significant fatty streak lesions at the aortic root [6]. In pioneering studies of inbred mouse strains, Paigen et al. [4] examined the location and timing of lesion formation when mice were fed with the same atherogenic diet as used in the present study and they found that foam cells were present at the aortic root of C57BL/6 mice 6 weeks after initiation of the diet, and after 14 weeks on the diet, significant aortic lesions developed. However, at this stage, C57BL/6 mice displayed significant chronic inflammation in the liver $[13,14]$ and developed gall stone [15]. The mice with gall stone are frequently accompanied by marked elevations in plasma cholesterol levels and tend to develop larger aortic lesions.

Although old mice on atherogenic diet exhibited a moderate increase in plasma non-HDL cholesterol levels, they showed no increases in atherosclerotic lesion size compared with young mice. One explanation for the dissociation between non-HDL and atherosclerosis is that the lower triglyceride levels of old mice may have damped the effect of elevated non-HDL levels on lesion formation. On both chow and atherogenic diets, old mice exhibited a significant reduction in plasma triglyceride levels relative to young mice. An age-related reduction in triglyceride levels has also been observed in male rabbits [16]. In contrast, in humans, aging is accompanied by increased levels of triglycerides, total cholesterol and non-HDL and decreased levels of HDL $[17,18]$. Although there is no adequate evidence to explain the difference in changes of plasma lipid levels with age between humans and mice, the difference in the estrus cycle between these species may be an explanation. The estrus cycle of mice is not as obvious as that of humans, and the plasma estradiol level of mice does not show significant fluctuation. Elevated estrogen levels are associated with significant reductions in plasma non-HDL cholesterol and triglyceride levels [19]. Both young and old mice on atherogenic diet exhibited a reduction in triglyceride levels. Previous studies also showed that feeding of the atherogenic diet results in a reduction in triglyceride levels $[6,7,20]$. Cholate in the atherogenic diet inhibits cholesterol 7a-hydroxylase activity and was probably responsible for the reduction.

In the current study, we observed a significant increase in circulating VCAM-1 levels with age and also when fed the atherogenic diet in mice. A similar finding has been observed in apolipoprotein-E-deficient and LDL receptor-deficient mice $[8,21,22]$. Although the origin of this circulating adhesion molecule has not been clarified, it is most likely derived from shedding or proteolytic cleavage from endothelial cells on which this molecule is originally expressed [23]. Thus, a higher level of soluble VCAM-1 may reflect higher expression of VCAM-1 in the arterial wall. Indeed, we observed an increase in VCAM-1 expression in the aortic wall of old mice by Western blot analysis, although this increase did not reach statistical significance. VCAM-1 expressed by endothelial cells mediates adhesion to and rolling of monocytes along the endothelial border. All phases of atherosclerosis involve the recruitment of monocytes from circulation and their transendothelial migration. This process is predominantly mediated by cellular adhesion molecules expressed on the endothelium. VCAM-1 domain 4 deficiency markedly reduces arterial VCAM-1 expression, monocyte adherence in the aortic root and fatty streak formation in apolipoprotien-E-deficient mice [24]. Thus, increases in the expression of this adhesion molecule by vascular wall cells were expected to lead to more monocytes recruited to the subendothelium of arteries, where they differentiate, take up lipids and form foam cells. Surprisingly, increased VCAM-1 expression in the aortic wall with age was not accompanied by an increase in aortic lesions. Studies of human populations also show that circulating VCAM-1 is an age-dependent parameter independent of cardiovascular risk [25].

In summary, the present observation that old mice fed with the atherogenic diet had higher total cholesterol and soluble VCAM-1 levels compared with young mice but exhibited no increase in susceptibility to atherosclerosis indicates that higher susceptibility to the expression of known risk factors may not lead to increased atherosclerotic lesion formation. This finding is in support of the concept that factors other than plasma lipids modulate atherosclerosis susceptibility [26]. Moreover, the demonstration that age has little influence on atherosclerosis susceptibility provides an indirect proof that the increased cardiovascular incidence with age is due to a progressive increase in plaque size or increased exposure to risk factors leading to plaque rupture that causes clinical events.

\section{Acknowledgement}

This work was supported by National Institutes of Health grant HL71844. 


\section{References}

$\checkmark 1$ Orlandi A, Marcellini M, Spagnoli LG: Aging influences development and progression of early aortic atherosclerotic lesions in cholesterol-fed rabbits. Arterioscler Thromb Vasc Biol 2000;20:1123-1136.

-2 Spagnoli LG, Orlandi A, Mauriello A, Santeusanio G, De Angelis C, Lucreziotti R, Ramacci MT: Aging and atherosclerosis in the rabbits. 1. Distribution, prevalence and morphology of atherosclerotic lesions. Atherosclerosis 1991;89:11-24.

3 Cortes MJ, Diez-Juan A, Perez P, Perez-Roger I, Arroyo-Pellicer R, Andres V: Increased early atherogenesis in young versus old hypercholesterolemic rabbits by a mechanism independent of arterial cell proliferation. FEBS Lett 2002;522:99-103.

$\checkmark 4$ Paigen B, Morrow A, Holmes PA, Mitchell D, Williams RA: Quantitative assessment of atherosclerotic lesions in mice. Atherosclerosis 1987;68:231-240.

$\checkmark 5$ Zou Y, Yoon S, Jung KJ, Kim CH, Son TG, Kim MS, Kim YJ, Lee J, Yu BP, Chung HY: Upregulation of aortic adhesion molecules during aging. J Gerontol A Biol Sci Med Sci 2006;61:232-244.

6 Shi W, Wang X, Shih DM, Laubach VE, Navab M, Lusis AJ: Paradoxical reduction of fatty streak formation in mice lacking endothelial nitric oxide synthase. Circulation 2002;105:2078-2082.

7 Shi W, Wang X, Tangchitpiyanond K, Wong J, Shi Y, Lusis AJ: Atherosclerosis in C3H/HeJ mice reconstituted with apolipoprotein $\mathrm{E}$ null bone marrow. Arterioscler Thromb Vasc Biol 2002;22:650-655.

8 Tian J, Pei H, James JC, Li Y, Matsumoto AH, Helm GA, Shi W: Circulating adhesion molecules in apoE-deficient mouse strains with different atherosclerosis susceptibility. Biochem Biophys Res Commun 2005;329:11021107.

9 Su Z, Li Y, James JC, McDuffie M, Matsumoto AH, Helm GA, Weber JL, Lusis AJ, Shi W: Quantitative trait locus analysis of atherosclerosis in an intercross between $\mathrm{C} 57 \mathrm{BL} / 6$ and $\mathrm{C} 3 \mathrm{H}$ mice carrying the mutant apolipoprotein E gene. Genetics 2006;172: 1799-1807.
10 Shi W, Wang X, Wong J, Hedrick CC, Wong H, Castellani LW, Lusis AJ: Effect of macrophage-derived apolipoprotein E on hyperlipidemia and atherosclerosis of LDLR-deficient mice. Biochem Biophys Res Commun 2004;317:223-229.

11 Quinn R: Comparing rat's to human's age: how old is my rat in people years? Nutrition 2005;21:775-777.

12 Paigen B, Holmes PA, Mitchell D, Albee D: Comparison of atherosclerotic lesions and HDL-lipid levels in male, female, and testosterone-treated female mice from strains C57BL/6, BALB/c, and C3H. Atherosclerosis 1987;64:215-221.

13 Liao F, Andalibi A, deBeer FC, Fogelman AM, Lusis AJ: Genetic control of inflammatory gene induction and NF-kappa B-like transcription factor activation in response to an atherogenic diet in mice. J Clin Invest 1993;91:2572-2579.

14 Liao F, Andalibi A, Qiao JH, Allayee H, Fogelman AM, Lusis AJ: Genetic evidence for a common pathway mediating oxidative stress, inflammatory gene induction, and aortic fatty streak formation in mice. J Clin Invest 1994;94:877-884.

15 Khanuja B, Cheah YC, Hunt M, Nishina PM, Wang DQ, Chen HW, Billheimer JT, Carey MC, Paigen B: Lith1, a major gene affecting cholesterol gallstone formation among inbred strains of mice. Proc Natl Acad Sci USA 1995;92:7729-7733.

16 Yamada S, Ito T, Tamura T, Shiomi M: Agerelated changes in serum/plasma biochemical parameters of WHHLMI rabbits. Exp Anim 2004;53:159-163.

17 Bruunsgaard H, Skinhoj P, Pedersen AN, Schroll M, Pedersen BK: Ageing, tumour necrosis factor-alpha (TNF-alpha) and atherosclerosis. Clin Exp Immunol 2000;121:255260.

18 Matthan NR, Jalbert SM, Lamon-Fava S, Dolnikowski GG, Welty FK, Barrett HR, Schaefer EJ, Lichtenstein AH: TRL, IDL, and LDL apolipoprotein B-100 and HDL apolipoprotein A-I kinetics as a function of age and menopausal status. Arterioscler Thromb Vasc Biol 2005;25:1691-1696.
19 Nathan L, Shi W, Dinh H, Mukherjee TK, Wang X, Lusis AJ, Chaudhuri G: Testosterone inhibits early atherogenesis by conversion to estradiol: critical role of aromatase. Proc Natl Acad Sci USA 2001;98:3589-3593.

-20 Mehrabian M, Castellani LW, Wen PZ, Wong J, Rithaporn T, Hama SY, Hough GP, Johnson D, Albers JJ, Mottino GA, Frank JS, Navab M, Fogelman AM, Lusis AJ: Genetic control of HDL levels and composition in an interspecific mouse cross (CAST/Ei $\times$ C57BL/6J). J Lipid Res 2000;41:1936-1946.

21 Merat S, Fruebis J, Sutphin M, Silvestre M, Reaven PD: Effect of aging on aortic expression of the vascular cell adhesion molecule-1 and atherosclerosis in murine models of atherosclerosis. J Gerontol A Biol Sci Med Sci 2000;55:B85-B94.

22 Tian J, Pei H, Sanders JM, Angle JF, Sarembock IJ, Matsumoto AH, Helm GA, Shi W: Hyperlipidemia is a major determinant of neointimal formation in LDL receptor-deficient mice. Biochem Biophys Res Commun 2006;345:1004-1009.

23 Gearing AJ, Newman W: Circulating adhesion molecules in disease. Immunol Today 1993;14:506-512.

24 Dansky HM, Shu P, Donavan M, Montagno J, Nagle DL, Smutko JS, Roy N, Whiteing S, Barrios J, McBride TJ, Smith JD, Duyk G, Breslow JL, Moore KJ: A phenotype-sensitizing ApoE-deficient genetic background reveals novel atherosclerosis predisposition loci in the mouse. Genetics 2002;160:15991608.

25 Richter V, RassoulF, PurschwitzK, Hentschel B, Reuter W, Kuntze T: Circulating vascular cell adhesion molecules VCAM-1, ICAM-1, and E-selectin in dependence on aging. Gerontology 2003;49:293-300.

26 Pei H, Wang Y, Miyoshi T, Zhang Z, Matsumoto AH, Helm GA, Tellides G, Shi W: Direct evidence for a crucial role of the arterial wall in control of atherosclerosis susceptibility. Circulation 2006;114:2382-2389. 